\title{
Kinetics of austenite formation during continuous heating in a low carbon steel
}

\author{
F.L.G. Oliveira ${ }^{\text {a }}$, M.S. Andrade ${ }^{\mathrm{b}}$, A.B. Cota ${ }^{\mathrm{c}, *}$ \\ ${ }^{a}$ REDEMAT, Federal University of Ouro Preto, Ouro Preto, MG, Brazil \\ ${ }^{\mathrm{b}}$ Fundação Centro Tecnológico de Minas Gerais - CETEC - 31170-000, Belo Horizonte, MG, Brazil \\ c Department of Physics, Federal University of Ouro Preto, Campus Universitário, CEP 35400-000, Ouro Preto, Brazil
}

Received 16 March 2006; accepted 29 April 2006

\begin{abstract}
The kinetics and microstructural evolution of austenite formation in a low carbon steel, with initial microstructure composed of ferrite and pearlite, were studied during continuous heating, by using dilatometric analysis and measurements of microstructural parameters. The formation of austenite was observed to occur in two stages: (a) pearlite dissolution and (b) ferrite to austenite transformation. The critical temperatures of austenite formation in continuous heating increase with increasing heating rate, with greater influence on the finishing temperature of austenite formation. For both the $1{ }^{\circ} \mathrm{C} / \mathrm{s}$ and $0.1{ }^{\circ} \mathrm{C} / \mathrm{s}$ heating rates, the formation rate of austenite reaches a maximum at approximately the finishing temperature of pearlite dissolution, and the formation rate of austenite as a function of the temperature is greater at the higher heating rate.
\end{abstract}

(C) 2006 Elsevier Inc. All rights reserved.

Keywords: Low carbon steel; Austenite formation; Continuous heating transformation; Kinetics

\section{Introduction}

The formation of austenite in carbon steels is very important in commercial processes, because the steels are frequently processed in the austenitic field in some industrial steps. These include most thermomechanical and thermochemical treatments. The initial condition of the austenite determines the development of the final microstructure and the mechanical properties of the material. In this sense, the mechanical properties of the steels depend on the kinetics of austenite formation; in others words, they depend on the heating rate, austenite

\footnotetext{
* Corresponding author. Tel.: +55 313559 1368; fax: +55 313559 1370.

E-mail address: abcota@ufop.br (A.B. Cota).
}

homogeneity, austenite grain size, non-metallic inclusions, and the distribution, size and chemistry of individual phases [1].

In recent years, several models describing the kinetics of austenite formation during heating have been proposed. Nevertheless, these studies are not as well developed as those for the decomposition of austenite into ferrite and pearlite during continuous cooling [2-4]. Since dilatometric analysis is a technique very often employed to study phase transformation kinetics in steels, the relative change in length which occurs during austenite formation has been studied as a function of temperature. Both kinetics and/or dilatometric analysis have been used to validate the model proposed for non-isothermal austenite formation in steels [5-7]. 


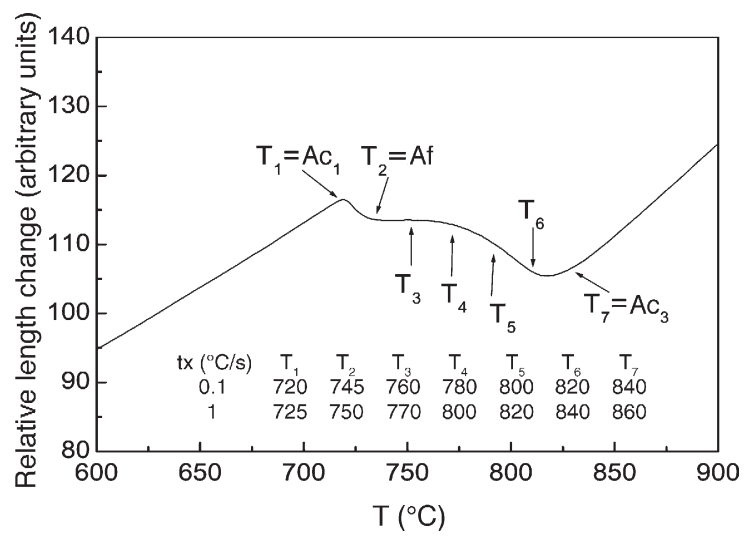

Fig. 1. Temperatures selected from heating dilatometric curves to investigate the progress of austenite.

The formation of austenite during heating differs in many ways from those transformations that occur during the cooling of austenite. The kinetics of austenite decomposition can be described satisfactorily in terms of the chemical composition and the austenite grain size, but the kinetics of austenite formation is influenced by chemical composition, initial microstructure and the heating rate [2-7].

This work analyzes the influence of the heating rate on the kinetics and microstructural evolution of austenite formation in the continuous heating of a low carbon steel with initial microstructure composed of ferrite and pearlite, by using dilatometric analysis and measurements of microstructural parameters. The continuous heating transformation diagram of the steel was also obtained.

\section{Materials and experimental procedure}

The chemical composition of the steel under investigation, expressed in wt.\%, was $0.15 \mathrm{C}, 1.42 \mathrm{Mn}$, $0.37 \mathrm{Si}, 0.052 \mathrm{Al}, 0.031 \mathrm{Nb}, 0.023 \mathrm{P}, 0.009 \mathrm{~S}, 0.0042 \mathrm{~N}$, bal Fe.

The dilatometric analysis was carried out using an Adamel-Lhomargy LK 02 quenching dilatometer. Cylindrical $2 \mathrm{~mm}$ diameter, $12 \mathrm{~mm}$ long samples were used. The critical temperatures of austenite formation were determined from the dilatometric curves. The continuous heating transformation diagram was constructed for heating rates of $0.1,1,5,10,13$ and $16^{\circ} \mathrm{C} / \mathrm{s}$.

Several quenching temperatures were selected in order to investigate the progress of the austenite formation. Fig. 1 shows, on a dilatometric curve, the seven temperatures at which heating was interrupted by quenching (He gas). This procedure was performed in the dilatometer for heating rates of 0.1 and $1.0{ }^{\circ} \mathrm{C} / \mathrm{s}$.
The microstructural characterization was carried out by light microscopy and atomic force microscopy (AFM). The AFM images were obtained in Dimension 3000 equipment using commercial silicon tips in the tapping mode. The volume fractions of the constituents were determined with the aid of a digital image processing program, linked to the optical microscope. For examination of the microstructure, 2\% nital and LePera's etchants [8] were used. Samples for AFM observations required fine polishing and a lighter etch.

\section{Results and discussion}

The initial microstructure of the samples consists of pearlite and ferrite (volume fraction of $0.73 \pm 0.03$ ) and an average grain size of $18 \pm 0.6 \mu \mathrm{m}$.

\subsection{Continuous heating transformation diagram (CHT)}

The dilatometric curve of length change as a function of temperature, $\Delta L / L_{0}=f(T)$, and its corresponding derivative, $\mathrm{d}\left(\Delta L / L_{0}\right) / \mathrm{d} T=f(T)$, is illustrated in Fig. 2 for the heating rate of $1{ }^{\circ} \mathrm{C} / \mathrm{s}$. The critical temperatures $\mathrm{Ac}_{1}$ (starting temperature of austenite formation), Af (finishing temperature for the dissolution of pearlite) and $\mathrm{Ac}_{3}$ (finishing temperature of austenite formation) are indicated in the figure. It is observed that austenite formation occurs in two stages. The first stage is the pearlite dissolution and is characterized by the first peak of contraction in the dilatometric curve. It starts at $\mathrm{Ac}_{1}$ and finishes at Af. The second stage is the ferrite to austenite transformation and is characterized by the second peak of contraction. It starts at $\mathrm{Af}$ and finishes at $\mathrm{Ac}_{3}$. Both transformations take place by nucleation and growth processes.

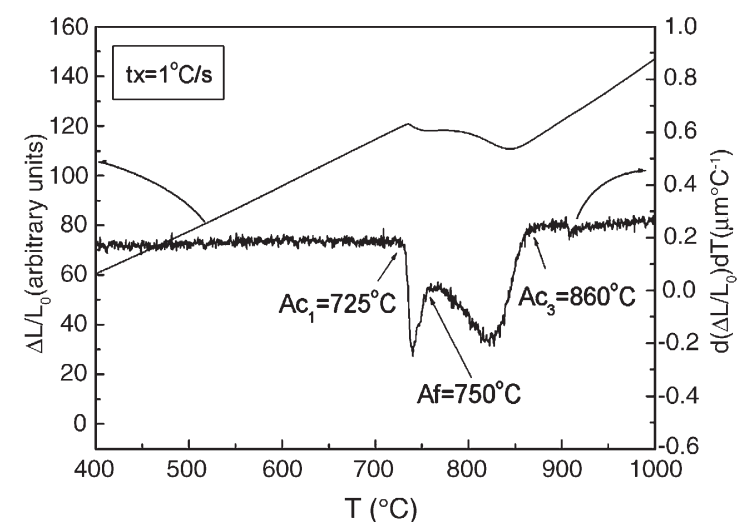

Fig. 2. Dilatometric curve of length change as a function of temperature and its corresponding derivative, for the heating rate of $1{ }^{\circ} \mathrm{C} / \mathrm{s}$. 
This characteristic of austenite formation of an initial microstructure consisting of ferrite and pearlite has been described in recent papers [3-5]. The nucleation of austenite inside pearlite takes place preferentially at the points of intersection of cementite with the edges of the pearlite colony. Austenite nuclei in pearlite grow when carbon atoms are transported through the austenite by diffusion from the austenite/cementite boundary to the ferrite/austenite boundary and from the ferrite/cementite boundary through the ferrite, resulting in a transformation of the ferrite to austenite.

Fig. $3 \mathrm{~A}$ and $\mathrm{B}$ show images of the sample microstructure heated at $1{ }^{\circ} \mathrm{C} / \mathrm{s}$ and quenched at $750{ }^{\circ} \mathrm{C}$ (Af temperature). The microstructure consists of:

- the ferrite $(\alpha)$, that was not transformed into austenite at this temperature,

- and martensitic and bainitic products of the austenite decomposition on quenching.

The volume fraction of martensite and bainite was measured as $0.30 \pm 0.03$ and this value is approximately
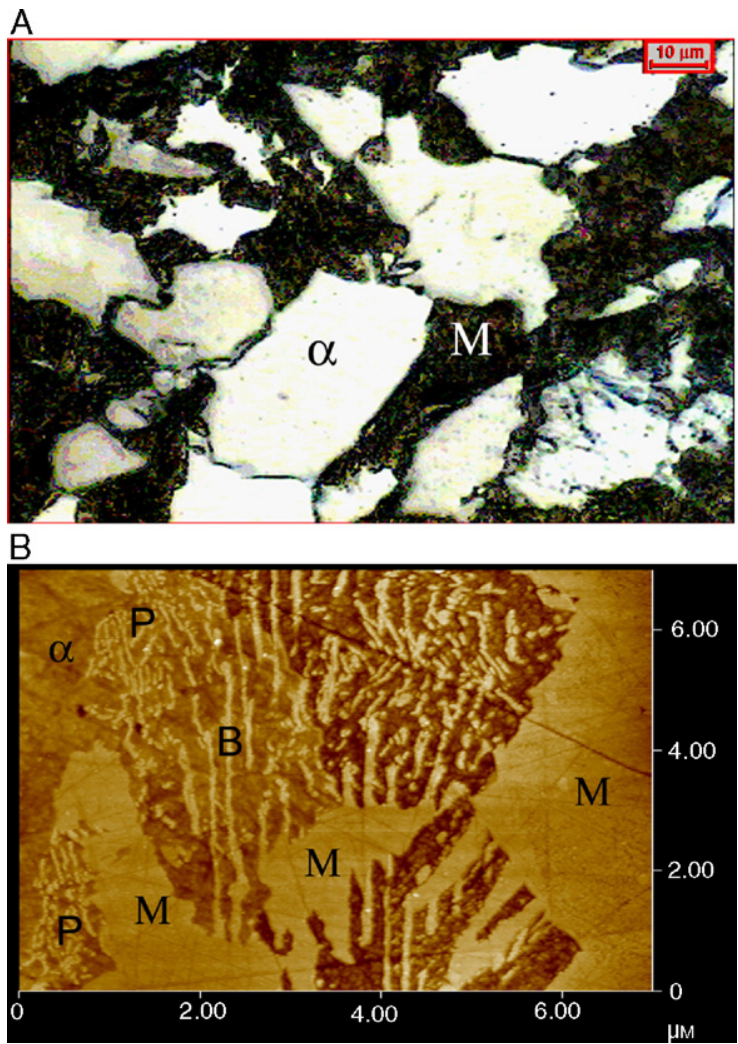

Fig. 3. Images of the sample microstructure heated at $1{ }^{\circ} \mathrm{C} / \mathrm{s}$ and quenched at $750{ }^{\circ} \mathrm{C}$ : (A) optical microscopy and (B) atomic force microscopy. Nital $2 \%$. $\alpha$ is ferrite, $\mathrm{B}$ is bainite, $\mathrm{P}$ is pearlite and $\mathrm{M}$ is martensite.

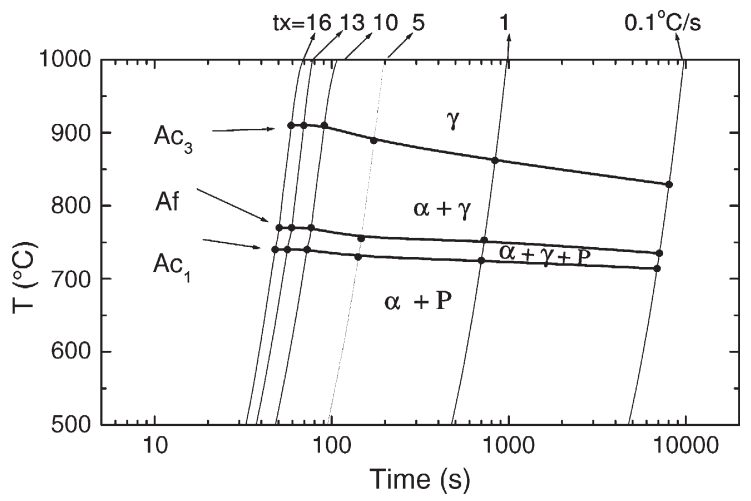

Fig. 4. Continuous heating transformation diagram for the steel. The range of heating rates studied covers from 0.1 to $16^{\circ} \mathrm{C} / \mathrm{s}$. $\alpha$ is ferrite, $\mathrm{P}$ is pearlite and $\gamma$ is austenite.

equal to the volume fraction of pearlite present in the initial microstructure of the steel $(0.27 \pm 0.3)$.

Fig. 4 shows the continuous heating transformation diagram (CHT) obtained for this steel. The range of heating rates studied is 0.1 to $16^{\circ} \mathrm{C} / \mathrm{s}$. A review of this diagram reveals the significant influence of the heating rate on the critical temperatures, which rise as the heating rate increases. The effect is much more pronounced on the $\mathrm{Ac}_{3}$ temperature.

Fig. 5 shows the values of $\Delta T_{1}=\left(\mathrm{Ac}_{3}-\mathrm{Ac}_{1}\right), \Delta T_{2}=$ $\left(\mathrm{Ac}_{3}-\mathrm{Af}\right)$ and $\Delta T_{3}=\left(\mathrm{Af}-\mathrm{Ac}_{1}\right)$ as a function of heating rate. These values increase with the heating rate, with a relatively greater influence at lower rates. The value of $\Delta T_{3}\left(\mathrm{Af}-\mathrm{Ac}_{1}\right)$ varied only a little.

\subsection{Kinetics of austenite formation}

The kinetics and microstructural evolution were studied for the heating rates of 0.1 and $1.0{ }^{\circ} \mathrm{C} / \mathrm{s}$. Fig. 6

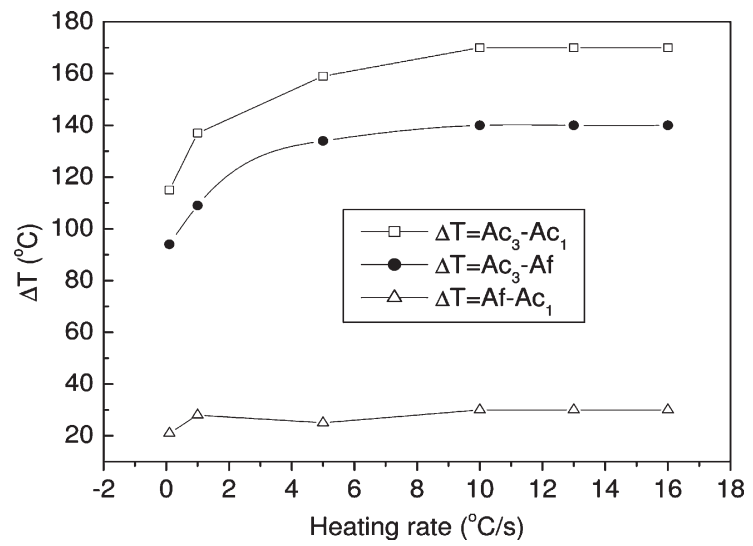

Fig. 5. Effect of the heating rate on the values $\Delta T_{1}=\left(\mathrm{Ac}_{3}-\mathrm{Ac}_{1}\right)$, $\Delta T_{2}=\left(\mathrm{Ac}_{3}-\mathrm{Af}\right)$ and $\Delta T_{3}=\left(\mathrm{Af}-\mathrm{Ac}_{1}\right)$. 
A

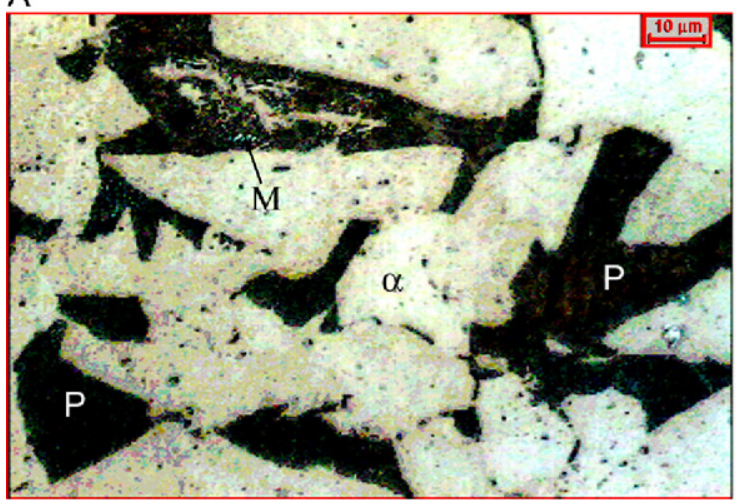

C

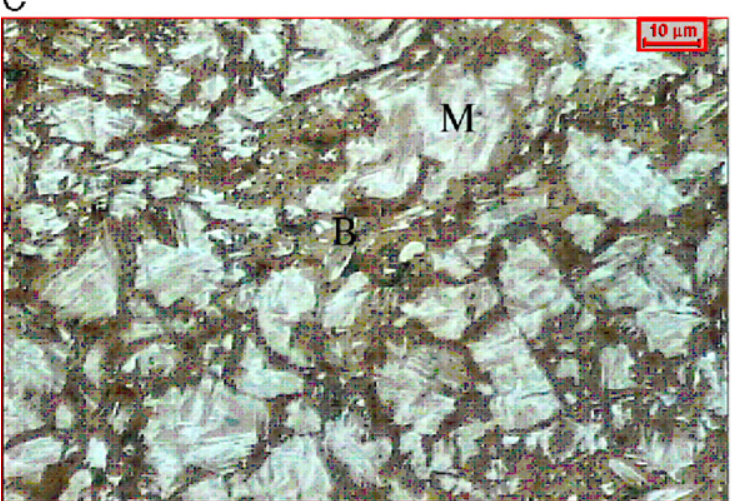

E

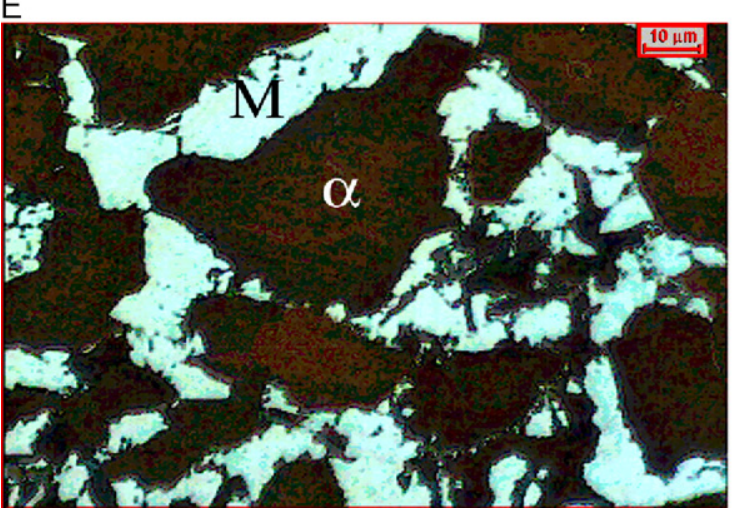

B

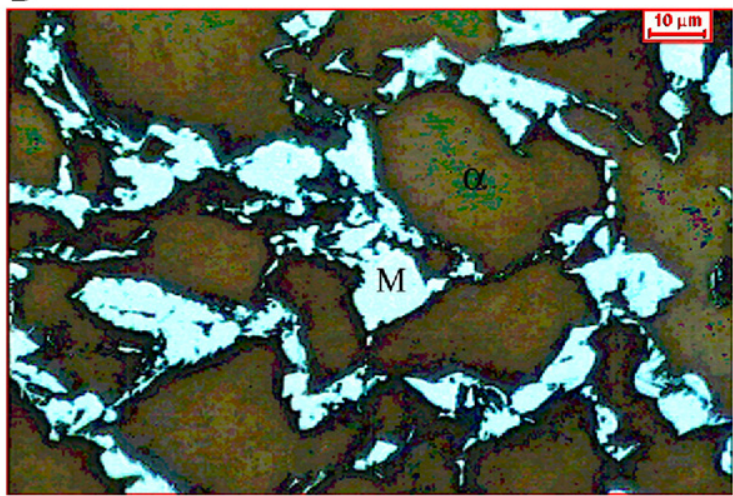

D
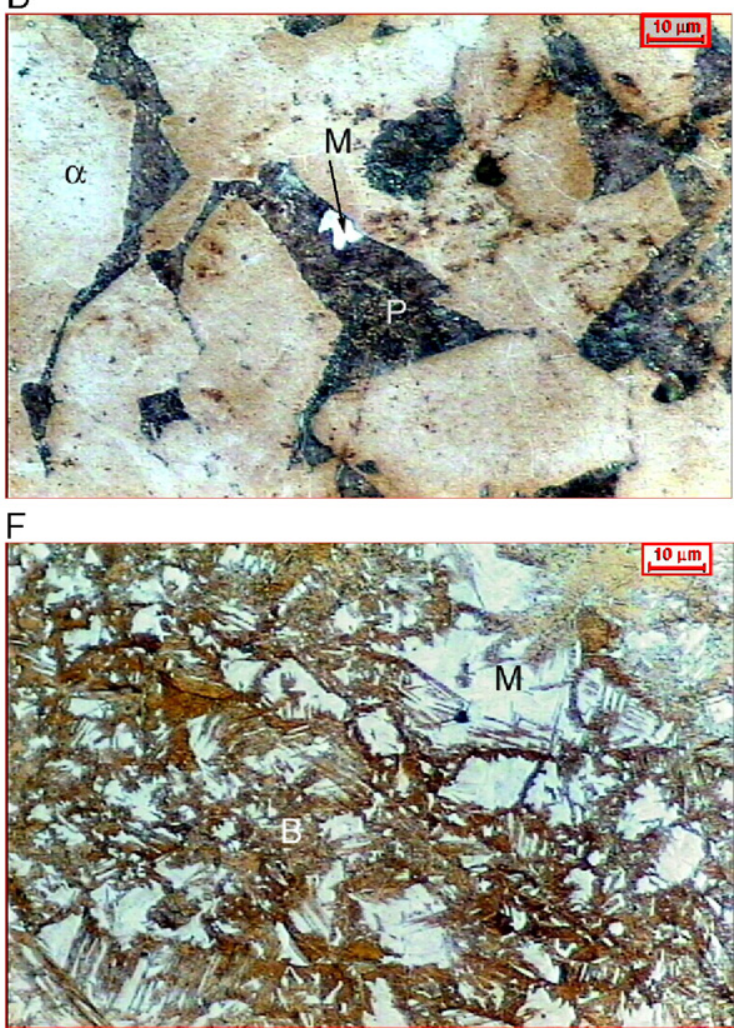

Fig. 6. Optical microscopy of samples heated at $0.1{ }^{\circ} \mathrm{C} / \mathrm{s}$ and quenched from (A) $720{ }^{\circ} \mathrm{C}\left(\mathrm{Ac}_{1}\right)$, (B) $745^{\circ} \mathrm{C}$ (Af) and (C) $840{ }^{\circ} \mathrm{C}(\mathrm{Ac})_{3}$ ); samples heated at $1.0^{\circ} \mathrm{C} / \mathrm{s}$ and quenched from (D) $725^{\circ} \mathrm{C}\left(\mathrm{Ac}_{1}\right),(\mathrm{E}) 750{ }^{\circ} \mathrm{C}(\mathrm{Af})$ and $(\mathrm{F}) 860^{\circ} \mathrm{C}\left(\mathrm{Ac}_{3}\right)$. LePera's etchant. $\alpha$ is ferrite, $\mathrm{P}$ is pearlite, $\mathrm{B}$ is bainite and $\mathrm{M}$ is martensite.

shows images of the microstructural evolution of austenite, by optical microscopy of the products of austenite decomposition on quenching from $\mathrm{Ac}_{1}$, Af and $\mathrm{Ac}_{3}$. Samples heated at $0.1^{\circ} \mathrm{C} / \mathrm{s}$ are shown in Fig. $6 \mathrm{~A}-\mathrm{C}$, and samples heated at $1.0^{\circ} \mathrm{C} / \mathrm{s}$ are presented in Fig. $6 \mathrm{D}-\mathrm{F}$.

Fig. 7 describes the evolution of the volume fractions of ferrite and austenite as a function of the temperature for these two heating rates. It is observed in Fig. 6 that the pearlite dissolution is very fast and is completed $25{ }^{\circ} \mathrm{C}$ above $\mathrm{Ac}_{1}$ for the heating rates shown; compare, e.g., Fig. $6 \mathrm{~A}$ and $\mathrm{B}$ for the $0.1^{\circ} \mathrm{C} / \mathrm{s}$ heating rate, and Fig. $6 \mathrm{D}$ and $\mathrm{E}$ for the $1.0{ }^{\circ} \mathrm{C} / \mathrm{s}$ heating rate. After the dissolution of ferrite it is observed that the austenite volume fraction is greater for the heating rate of $0.1{ }^{\circ} \mathrm{C} / \mathrm{s}$ than for the heating rate of $1.0{ }^{\circ} \mathrm{C} / \mathrm{s}$ at the same temperature.

The austenite volume fraction were fitted to the Avrami equation [9], expressed by:

$$
V=1-\exp \left(-K t^{n}\right)
$$


where $K$ and $n$ are constants determined in the curve fitting of the austenite volume fraction $(V)$ as a function of the transformation time $(t)$. The values of $K$ and $n$ are listed in Table 1, for the two heating rates.

The parameter $K$ represents the influence of the heating rate on the nucleation and growth rates of austenite, i.e. on the formation rate of austenite. A closer look into the parameters adjusted for the Avrami equation reveals that the parameter $K$ associated with the austenitization kinetics for the heating rate of $0.1{ }^{\circ} \mathrm{C}$ is two orders of magnitude lower than for the heating rate of $1.0{ }^{\circ} \mathrm{C} / \mathrm{s}$. The parameter $n$ is practically independent of the heating rate and its value is similar to the value of 1.6 predicted by Zhang et al. [10].

Fig. 8 shows the formation rate of austenite on continuous heating. For both heating rates, $1.0^{\circ} \mathrm{C} / \mathrm{s}$ and $0.1{ }^{\circ} \mathrm{C} / \mathrm{s}$, the formation rate of austenite reaches the maximum at approximately the finishing temperature of pearlite dissolution, and the formation rate of austenite as a function of temperature is greater at the higher heating rate.

The growth rate of austenite is believed to be controlled by either volume diffusion of carbon or by boundary diffusion of substitutional alloying elements. If the growth rate of austenite is controlled by the bulk diffusion of atoms in austenite ahead of the interface, the diffusion of carbon may play a more important role than that of the substitutional alloying elements. Diffusivity of the substitutional alloying elements in austenite is far slower than that of carbon, and the substitutional alloying elements may not diffuse a long distance during the reaction. However, as described by Porter and Easterling [11], at the lower temperatures, boundary diffusion of substitutional alloying elements is the dominant mechanism in the diffusion process. It can be supposed that for the heating rate of $1.0{ }^{\circ} \mathrm{C} / \mathrm{s}$ the growth rate of austenite is primarily controlled by the volume diffusion of carbon in austenite, due to the fact that the transformation takes place mostly at higher temperatures (parameter $K=2 \times 10^{-3}$ ). Conversely, at heating rates of $0.1^{\circ} \mathrm{C} / \mathrm{s}$ the growth rate of austenite may be assumed to be controlled by boundary diffusion of substitutional alloying elements [4] (parameter $\left.K=7 \times 10^{-5}\right)$. Hence, the growth rate of austenite is

Table 1

Values of the parameters $K$ and $n$ of the Avrami's equation for the two heating rates

\begin{tabular}{lll}
\hline Heating rate $\left({ }^{\circ} \mathrm{C} / \mathrm{s}\right)$ & $K$ & $n$ \\
\hline 0.1 & $7 \times 10^{-5}$ & 1.5 \\
1.0 & $2 \times 10^{-3}$ & 1.4 \\
\hline
\end{tabular}

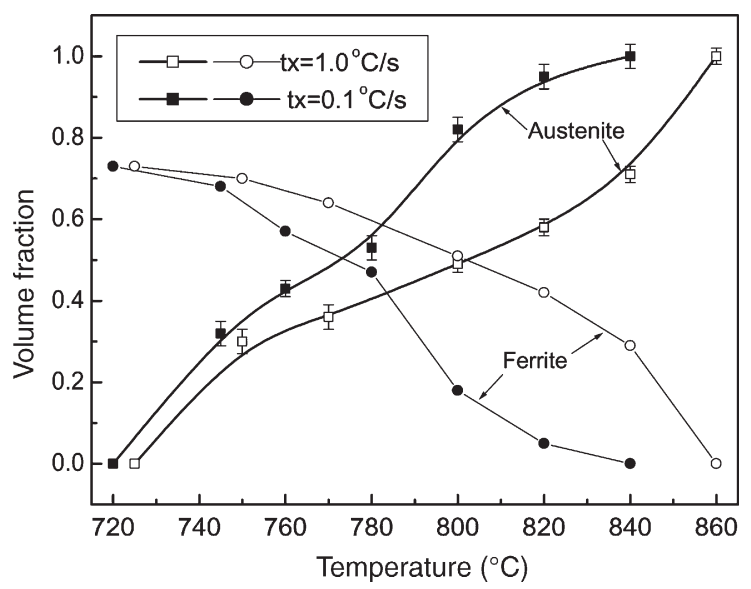

Fig. 7. Ferrite and austenite volume fraction as function of temperature for 0.1 and $1.0^{\circ} \mathrm{C} / \mathrm{s}$ heating rates.

greater for small time intervals for transformation at a heating rate of $1.0^{\circ} \mathrm{C} / \mathrm{s}$.

\section{Conclusions}

It was observed that austenite formation occurs in two stages. The first stage is the dissolution of pearlite, followed by the ferrite to austenite transformation. Both transformations take place by nucleation and growth processes.

The critical temperatures for austenite formation during continuous heating increase with increasing heating rate, which therefore exerts a greater influence on the finishing temperature of the austenite formation.

The parameter $K$ of the Avrami equation associated with the austenitization kinetics for a heating rate of $0.1{ }^{\circ} \mathrm{C}$ is two orders of magnitude lower than that found for a heating rate of $1.0^{\circ} \mathrm{C} / \mathrm{s}$. The parameter $K$ represents the influence of the heating rate on the nucleation and

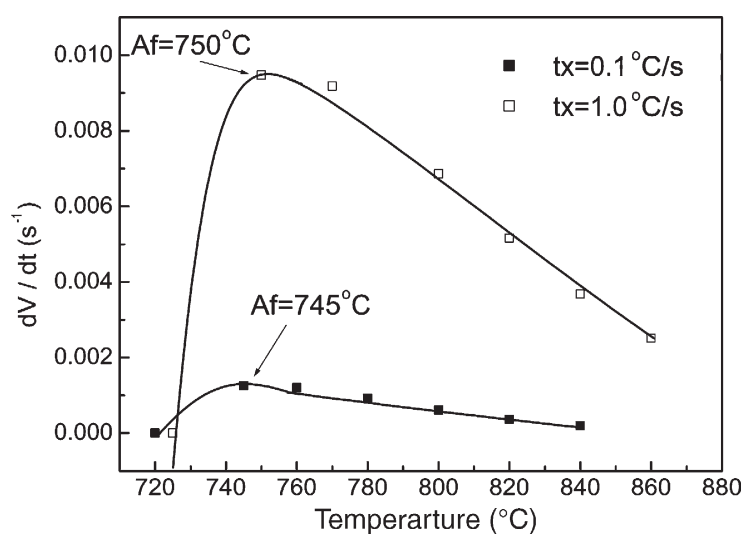

Fig. 8. Formation rate of austenite as a function of temperature for the two heating rates. $V$ is the austenite volume fraction. 
growth rates of austenite (formation rate of austenite). The parameter $\mathrm{n}$ in the Avrami equation is practically independent of the heating rate. Its values are 1.5 and 1.4 for the heating rates of 0.1 and 1.0 , respectively.

For both the heating rates of $1{ }^{\circ} \mathrm{C} / \mathrm{s}$ and $0.1{ }^{\circ} \mathrm{C} / \mathrm{s}$, the formation rate of austenite reaches a maximum at approximately the finishing temperature of pearlite dissolution, and the formation rate of austenite as a function of temperature is greater for the higher heating rate.

\section{Acknowledgements}

The authors are grateful for the financial support of $\mathrm{CNPq}$ and FAPEMIG.

\section{References}

[1] Krauss G. Steels: heat treatment and processing principles. Ohio: ASM International; 1990.

[2] Akbay T, Reed RC, Atkinson C. Modelling reaustenitisation from ferrite/cementite mixtures in $\mathrm{Fe}-\mathrm{C}$ steels. Acta Metall Mater 1994;47:469-1480.

[3] García de Andrés C, Caballero FG, Capdevila C, Bhadeshia $\mathrm{HKDH}$. Modelling of kinetics and dilatometric behavior of non- isothermal perlite-to-austenite transformation in an eutectoid steel. Scr Mater 1998;39:791-6.

[4] Caballero FG, Capdevila C, García de Andrés C. Modelling of kinetics of austenite formation in steels with different initial microstructures. ISIJ International 2001;41:1093-102.

[5] Reed RC, Akbay T, Shen Z, Robinson JM, Root JH. Determination of reaustenitisation kinetics in a $\mathrm{Fe}-0.4 \mathrm{C}$ steel using dilatometry and neutron diffraction. Mater Sci Eng A 1998;256:152-65.

[6] García de Andrés C, Caballero FG, Capdevila C. Dilatometric characterization of perlite dissolution in $0.1 \mathrm{C}-0.5 \mathrm{Mn}$ low carbon low manganese steel. Scr Mater 1998;38:1835-42.

[7] García de Andrés C, Caballero FG, Capdevila C, Álvarez LF. Application of dilatometric analysis to the study of solid-solid phase transformation in steels. Mater Charact 2002;48:101-11.

[8] LePera FS. Improved etching technique to emphasize martensite and bainite in high-strength-dual-phase steel. J Met 1980; 32:38-9.

[9] Avrami M. Transformation-time relations for random distribution of nuclei. kinetics of phase change: II. J Chem Phys 1940;8:212-24.

[10] Zhang W, Elmer JW, DebRoy T. Kinetics of ferrite to austenite transformation during welding of 1005 steel. Scr Mater 2002;46:753-7.

[11] Porter DA, Easterling KE. Phase transformation in metals and alloys. 2nd. London: Chapman \& Hall; 1992. p. 440. 